\title{
Profile of brazilian dental students and its relationship to anxiety levels
}

\section{Perfil dos alunos de odontologia e sua relação com os níveis de ansiedade}

Nayane Cavalcante Ferreira da Silva ${ }^{1}$. Bruno Rocha da Silva, M.Sc ${ }^{2}$. Hélvia Menezes Vasconcelos ${ }^{3}$. Patrícia Maria Costa de Oliveira, M.Sc ${ }^{4}$. Edson Holanda Teixeira, Ph.D ${ }^{5}$. Andréa Silvia Walter de Aguiar, Ph.D ${ }^{6}$.

1. Mestre, Universidade Federal do Ceará, Fortaleza, Brasil. 2. Mestre, Universidade de Fortaleza - UNIFOR, Fortaleza, Brasil. 3 Aluna de Pós-graduação, Universidade Federal do Ceará, Fortaleza, Brasil. 4 Professora substituta, Departamento de Clínica Odontológica, Universidade Federal do Ceará, Fortaleza, Brasil. 5 Professor adjunto, Departamento de Patologia e Medicina Legal, Universidade Federal do Ceará, Fortaleza, Brasil. 6 Professora adjunta, Departamento de Clínica Odontológica, Fortaleza, Brasil.

\section{ABSTRACT}

The aim of this study was to evaluate the profile of dental students and its relationship to anxiety levels. The State-Trait Anxiety Inventory was applied to 207 first- to fifth-year undergraduates enrolled in the dentistry program at the School of Pharmacy, Dentistry and Nursing, Federal University of Ceará, Brazil. Participants were aged 17 to 29 years, and the maiority were women $(57.5 \%)$. Students had a weekly workload of up to 40 hours and performed at least two complementary activities, in addition to their undergraduate training. Almost all students $(95.7 \%)$ had attended private high schools and $80.6 \%$ lived with their parents or spouses. Regarding parental education, $59.4 \%$ of mothers and $55.6 \%$ of fathers had a higher education degree. Most students showed medium levels of anxiety according to measurements of state anxiety $(53.1 \%)$ and trait anxiety (81.6\%). It can be concluded that more than $50 \%$ of students in the Dentistry graduation course of the Federal University of Ceará showed an average level of anxiety, and that the excessive workload and enrichment activities necessary to obtain the undergraduate degree in Dentistry probably can be influencing the anxiety levels of students, however, more studies and statistical tests should be performed to identify the root causes in order to preserve the mental health of these future dentists.

Keywords: Dentistry. Dental students. Anxiety. Test anxiety scale.

\section{RESUMO}

O objetivo deste estudo foi avaliar o perfil dos estudantes de odontologia e sua relação com os níveis de ansiedade. O Inventário de Ansiedade Traço-Estado foi aplicado a 207 alunos do primeiro ao quinto ano, matriculados no curso de Odontologia da Faculdade de Farmácia, Odontologia e Enfermagem da Universidade Federal do Ceará. Os participantes tinham entre 17 a 29 anos, e a maioria eram mulheres $(57,5 \%)$. Os alunos tiveram uma carga de aulas semanais de até 40 horas e realizaram pelo menos duas atividades complementares, além do curso de graduação. Quase todos os alunos (95,7\%) tinham frequentado escolas privadas e $80,6 \%$ viviam com seus pais ou cônjuges. Em relação à escolaridade dos pais, 59,4\% das mães e 55,6\% dos pais tinham um diploma de Ensino Superior. A maioria dos estudantes apresentaram níveis médios de ansiedade, ansiedade-estado $(53,1 \%)$ e ansiedade-traço $(81,6 \%)$. Pode-se concluir que mais de $50 \%$ dos alunos que frequentam o curso de Odontologia da Universidade Federal do Ceará demonstraram um nível médio de ansiedade, e que a carga horária excessiva e as atividades complementares necessárias para obtenção do título de graduação em Odontologia provavelmente podem estar influenciando os níveis de ansiedade dos alunos, entretanto, mais estudos e testes estatísticos devem ser realizados para identificar as principais causas, a fim de preservar a saúde mental desses futuros cirurgiões-dentistas.

Palavras-chave: Odontologia. Estudantes de odontologia. Ansiedade. Escala de ansiedade frente a teste.

Corresponding Author: Andréa Silvia Walter de Aguiar, Universidade Federal do Ceará. Monsenhor Furtado street, s/n, Rodolfo Teófilo, Fortaleza, Ceará, Brazil. Zip code: 60441-750. Telephone : + 5585 3366-8425. E-mail: aswaguiar@yahoo.com.br.

Conflict of interests: The authors have no conflicts of interest to declare.

Received: 27 Mai 2015; Revised: 09 Jun 2015; Accepted: 11 Jun 2015. 


\section{INTRODUCTION}

Anxiety can be defined as an emotional state that combines both physiological and psychological reactions. Anxiety is often triggered by feelings of fear in the face of imminent danger, which allows the affected person to take measures to deal with the threat, although the object that causes anxiety is not often identified. Anxiety, along with depression, has been regarded as one of the most common disorders affecting college students and may negatively affect their personal, social and professional lives. ${ }^{1,2,3}$

From the neurological point of view, anxiety can be classified as state- or trait-dependent. State anxiety is a transitory emotional state that consists of feelings of apprehension and tension experienced in a particular stressful situation. This state varies in intensity and fluctuates over time, being associated with heightened activity of the autonomic nervous system. Trait anxiety is an enduring personality trait (a stable characteristic), that is, an individual tendency to perceive stressful situations as dangerous or threatening, responding to such situations with an increase in anxiety intensity. $2,3,4$

The university environment is a major source of anxiety for many students in the health professions, such as dentistry, medicine and nursing. A wide variety of clinical and surgical practices, designed to develop psychomotor skills and involving technical complexities, have been shown to be closely related to high levels of anxiety among students, especially for students training to perform a new procedure. ${ }^{4}$

The early detection of anxiety in the college student population is therefore extremely important, because this disorder can heavily compromise the student's concentration and attention, health, academic performance, and the acquisition of new motor skills, negatively affecting the teaching-learning process. ${ }^{1,3,5}$

This study aimed to determine the demographic profile of dental students attending the School of Pharmacy, Dentistry and Nursing at the Federal University of Ceará, Brazil, and to establish a relationship with anxiety levels by assessing state and trait anxiety.

\section{MATERIALS AND METHODS}

This was a longitudinal, observational study of first- to fifthyear undergraduate students enrolled in the dentistry program at the School of Pharmacy, Dentistry and Nursing, Federal University of Ceará, Brazil. Data collection was conducted between May and June 2010.

The required sample size was calculated using Epi-Info version 6.04, based on the following parameters: standard error less than $5.0 \%, 95 \%$ confidence interval $(95 \% \mathrm{CI})$, and prevalence of $50 \%$ plus $20 \%$ related to sample loss, ${ }^{6}$ which determined the sample size of 217 students, distributed across the semesters according to the percentage calculated from the total number of students per period/semester (six months). The distribution of students per period was as follows: 1st period - 25 students $(11.54 \%)$; 2nd period - 23 students $(10.70 \%)$; 3rd period - 21 students $(9.85 \%)$; 4 th period - 26 students $(11.83 \%)$; 5th period and 6th period 22 students (10.14\%) each; 7th period - 16 students $(7.32 \%)$; 8 th period -18 students $(8.45 \%)$; 9 th period -25 students $(11.26 \%)$; and 10th period - 19 students $(8.73 \%)$. Inclusion criteria were: being regularly enrolled in the dentistry program and following the curriculum implemented in 2005; having participated in at least $70 \%$ of the required activities in the semester. Each semester has a specific amount of credits - class hours - that must be fulfilled by the student, allowing its approval and progression in the graduation program. Each credit corresponds to 16 class hours. Distribution of credits by semesters: 1st semester - 28; 2nd semester - 30; 3rd semester - 28; 4th semester - 29; 5th semester - 30; 6th semester - 34; 7th semester - 28; 8th semester - 30; 9 th semester - 33 and 10th semester - 30); and having not failed any discipline during the graduation course. The non-response rate was $4.6 \%$, and the final sample consisted of 207 students.

The study was approved by the Research Ethics Committee of Federal University of Ceará (protocol no. 102/10), and written informed consent was obtained from all participants. The study was conducted in accordance with the provisions of the Declaration of Helsinki and resolution 196/96 of the Brazilian National Health Council, which regulates research involving human subjects.

\section{State-Trait Anxiety Inventory}

The survey instrument was administered to the students during theoretical classes, with prior authorization of the subject professor. Initially, a questionnaire including questions about sociodemographic variables, such as housing, religion, income, and parental education, among others, was administered. Then, a validated Portuguese version of the State-Trait Anxiety Inventory (STAI) was used to assess students' levels of anxiety. ${ }^{7}$ The STAI is a selfadministered test, applied individually or in groups, composed of two different 4-point Likert-type scales designed to measure state anxiety (part I) and trait anxiety (part II). Each scale consists of 20 statements, for which the respondent gives an answer ranging from 1 to 4 , which results in a final score ranging from 20 to 80 , with higher scores correlating with greater anxiety. For data analysis, anxiety levels were divided as follows: 20 to 40 points $=$ low level of anxiety; 41 to 60 points = medium level of anxiety; and 61 to 80 points $=$ high level of anxiety.

\section{Statistical analysis}

Data obtained were analyzed with descriptive statistics and the chi-square test. The results were expressed as absolute values, univariate and bivariate score distributions (\%), and statistical measurements (minimum, maximum, mean, median, standard deviation, and coefficient of variation). Anxiety levels were determined from the arithmetic mean corresponding to each STAI statement, and the results were classified as follows: 1 to 3 - low level, 4 to 7 - medium 
level, and 8 to 10 - high level. ${ }^{8,9}$ Statistical analysis was performed using the Statistical Package for the Social Sciences version 17.0 (SPSS Inc., Chicago, IL, USA). The level of significance was set at $5 \%$.

\section{RESULTS}

The 207 students who participated in the study were evenly distributed across the semesters, with 69 (33.3\%) students enrolled in the initial period of the program (1st to $3 \mathrm{rd}$ semesters), $76(36.7 \%)$ in the middle of the program (4th to 7 th semesters), and $62(30.0 \%)$ in the final period (8th to 10 th semesters).

According to sociodemographic and economic characteristics, most students were women, aged 21 to 24 years, mostly unmarried and Catholic. Almost all students had attended private high schools, lived with their parents or spouses, did not work and had their expenses paid by the family (Table 1).

Regarding parental education, 59.4\% $(n=123)$ of mothers and $55.6 \%(\mathrm{n}=115)$ of fathers had a higher education degree. The mothers worked mainly in the following areas: pedagogy $(\mathrm{n}=32,15.5 \%)$, arts $(\mathrm{n}=10,4.8 \%)$, dentistry $(\mathrm{n}=$ $4,1.9 \%)$, and business administration $(\mathrm{n}=4,1.9 \%)$; whereas the fathers worked mainly in law $(\mathrm{n}=14,6.8 \%)$, business ( $\mathrm{n}$ $=13,6.3 \%)$, civil engineering $(\mathrm{n}=9,4.3 \%)$, medicine $(\mathrm{n}=6$, $2.9 \%)$, and dentistry $(\mathrm{n}=2,1.0 \%)$.

When analyzing academic variables, over half of the students succeeded in their first attempt to enter the dentistry program, while the others made two or more attempts (in Brazil, students must pass an entrance examination to attend college). The weekly working hours, corresponding to theoretical and practical lessons, ranged from 30 to 40 hours per week and most students performed research, extension and monitoring activities, alone or combined, but only a few participated in activities in a shift system (Table 2).

The values for state anxiety (part I) were higher than those obtained for trait anxiety (part II); however, mean values for both state and trait anxiety showed that students had medium levels of anxiety (Table 3 ).

With respect to the measurement of state anxiety (part I) by the STAI, just over half of the students showed medium levels of anxiety $(n=110,53.1 \%)$, while the others had low levels of anxiety $(\mathrm{n}=97,46.9 \%)$. Regarding trait anxiety (part II), most students had medium levels of anxiety ( $\mathrm{n}=$ $169,81.6 \%), 36$ students $(17.4 \%)$ had low levels of anxiety, and only two students $(1.0 \%)$ showed high levels of anxiety (Figure 1).

The results for anxiety levels (parts I and II) were also analyzed separately according to sex. The analysis of state anxiety (part I) revealed that most women had low levels of anxiety, while most men showed medium levels of anxiety. Regarding trait anxiety (part II), both women and men showed medium levels of anxiety (Table 4).

The two-tailed chi-square test revealed a strong association of STAI scores with weekly workload (p1) and academic activities (p2) undertaken by students, particularly extracurricular research, monitoring, and extension activities (activities outside the university environment through actions with the urban and rural communities in the form of programs, projects, courses, events and services) and training courses (courses directed to dental care and can be performed in hospitals or emergency dental services under the regime of duty) $(\mathrm{p}<0.000)$ (Table 5).

Figure 1 - Distribution of state-anxiety and trait-anxiety levels of students enrolled in the dentistry program at the School of Pharmacy, Dentistry and Nursing of the Federal University of Ceará, Brazil.

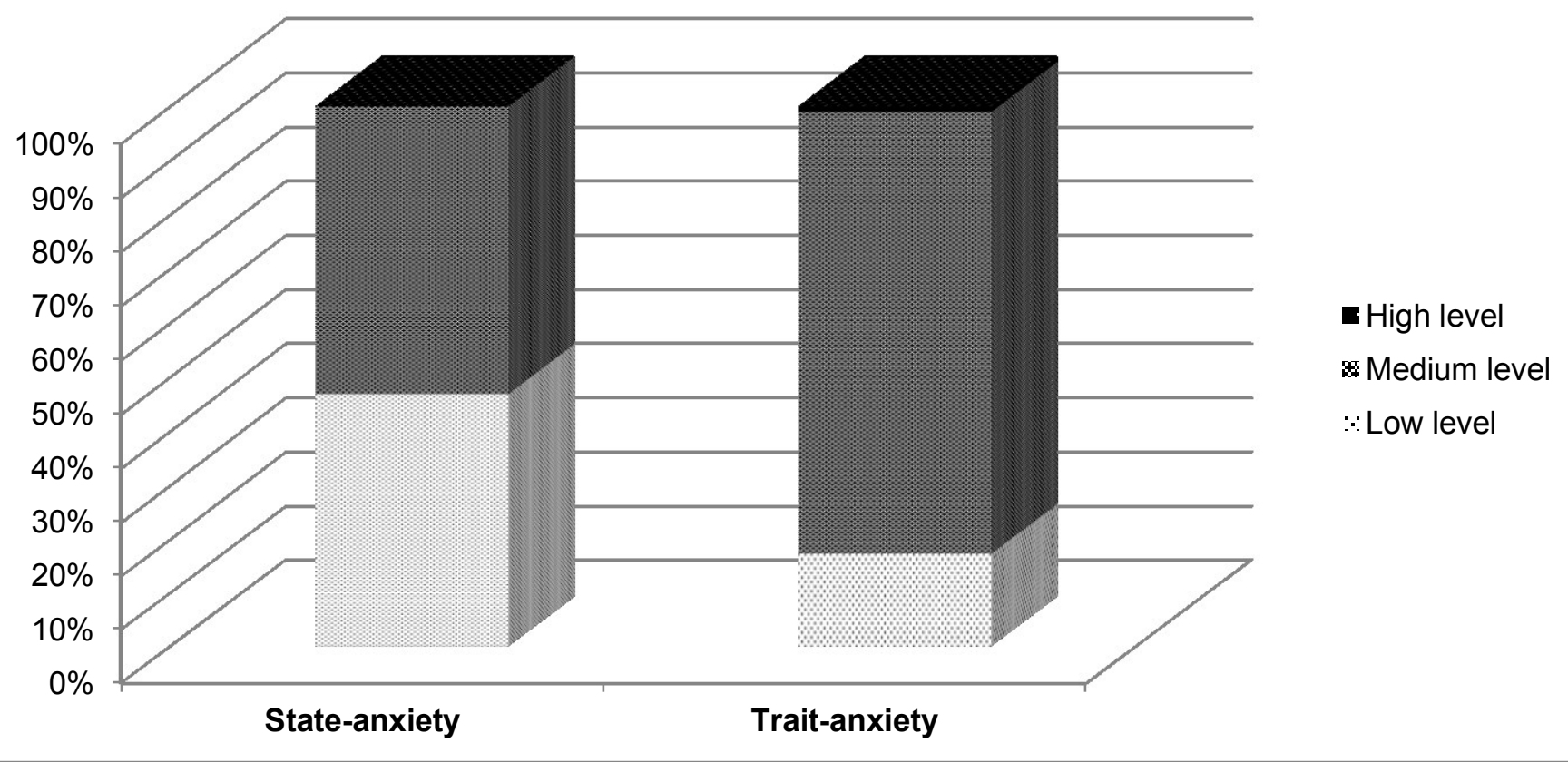


Table 1 - Distribution of students enrolled in the dentistry program at the School of Pharmacy, Dentistry and Nursing of the Federal University of Ceará, Brazil, according to sociodemographic and economic variables.

Variables

Not reported

\section{Age group}

17 to 20 years

21 to 24 years

More than 25 years

Not reported

\section{Marital status}

Single

Married

Separated/divorced

Not reported

\section{Religious belief}

Catholic

Evangelical

Agnostic/atheist

Other

Not reported

Housing

With parents

Alone

With other relatives/spouse

Other

Not reported

\section{Income}

$\begin{array}{ll}\text { Does not work } & 188\end{array}$

Works and receives financial support from the family

Works and provides financial support for the family

Not reported

\section{Completion of high school}

Public school

Private school

Not reported
$\mathrm{N}$

84

119

11

26

1.9 
Table 2 - Distribution of students enrolled in the dentistry program at the School of Pharmacy, Dentistry and Nursing of the Federal University of Ceará, Brazil, according to academic variables.

Variables

$\mathrm{N}$

$\%$

56.5

56.5

One

Two

Three

Four or more

Not reported

58

20

6

74

108

30 to 40 hours

More than 40 hours

Not reported

28.0

9.7

94.2

98.6

100.0

Up to 20 hours

20 to 30 hours

52.2

90.8

98.1

100.0

Weekly workload

Participation in other academic activities

Monitoring

Research

Extension

Not participating

Other

Research + monitoring

Monitoring + extension

Research + extension

Other + monitoring

More than two activities

Not reported

\section{Activities in a shift system}

Yes

No

Not reported

Total
18

187

2

207

\section{2}

15

4

7.2

1.9

3.4

3.9

11

54

38

3

10

22

22

2

33

1
5.3

26.2

18.4

1.4

4.8

10.6

10.6

1.0

15.9

.5

8.7

34.8

53.1

54.6

64.7

75.4

82.6

83.6

99.5

100.0

8.7

99.0

100.0

1.0

100.0

* In Brazil, students must pass an entrance examination to attend college.

Table 3 - State-anxiety (part I) and trait-anxiety (part II) values for students enrolled in the dentistry program at the School of Pharmacy, Dentistry and Nursing of the Federal University of Ceará, Brazil.

\begin{tabular}{llllll}
\hline & Minimum & Maximum & SD & Mean & Median \\
Part I & 28 & 59 & 0.435 & 41.34 & 41.00 \\
Part II & 34 & 62 & 0.434 & 45.30 & 45.00 \\
\hline
\end{tabular}

$\overline{\mathrm{SD}}=$ standard deviation. 
Table 4 - Distribution of state-anxiety (part I) and trait-anxiety (part II) levels according to sex among students enrolled in the dentistry program at the School of Pharmacy, Dentistry and Nursing of the Federal University of Ceará, Brazil.

\begin{tabular}{llll}
$\begin{array}{l}\text { Part I } \\
\mathrm{N}\end{array}$ & $\%$ & $\begin{array}{l}\text { Part II } \\
\mathrm{N}\end{array}$ & $\%$ \\
29 & 34.5 & 15 & 17.9 \\
55 & 65.5 & 68 & 81.0 \\
0 & 0 & 1 & 1.2 \\
& & & \\
65 & 54.6 & 19 & 16.0 \\
54 & 45.4 & 99 & 83.2 \\
0 & 0 & 1 & 0.8 \\
3 & & & \\
1 & 75.0 & 2 & 50.0 \\
207 & 25.0 & 2 & 50.0 \\
& 100 & 207 & 100 \\
\hline
\end{tabular}

Table 5 - Association of State-Trait Anxiety Inventory (STAI) scores with weekly workload (p1) and academic activities (p2) undertaken by students enrolled in the dentistry program at the School of Pharmacy, Dentistry and Nursing of the Federal University of Ceará, Brazil.

\begin{tabular}{|c|c|c|c|c|c|c|}
\hline & STAI & Yes & No & UD & Value of $p 1$ & Value of $\mathrm{p} 2$ \\
\hline \multirow{6}{*}{ 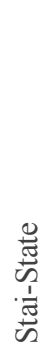 } & I feel comfortable & 27 & 24 & 03 & 0.000 & 0.000 \\
\hline & I feel upset & 120 & 118 & 02 & 0.000 & 0.000 \\
\hline & I am a nervous wreck & 119 & 118 & 01 & 0.000 & 0.000 \\
\hline & I am satisfied & 35 & 33 & 02 & 0.000 & 0.000 \\
\hline & I feel cheerful & 22 & 21 & 01 & 0.000 & 0.000 \\
\hline & I feel good & 17 & 16 & 01 & 0.000 & 0.000 \\
\hline \multirow{7}{*}{ 䔍 } & I feel good & 06 & 04 & 02 & 0.000 & 0.000 \\
\hline & I get tired easily & 30 & 29 & 01 & 0.000 & 0.000 \\
\hline & I would like to be happy & 105 & 103 & 02 & 0.000 & 0.000 \\
\hline & I am happy & 206 & 00 & 01 & 0.000 & 0.000 \\
\hline & I worry about the disappointments & 206 & 00 & 01 & 0.000 & 0.000 \\
\hline & I am a steady person & 205 & 00 & 02 & 0.000 & 0.000 \\
\hline & I get tense and upset & 206 & 00 & 01 & 0.000 & 0.000 \\
\hline
\end{tabular}

\section{DISCUSSION}

The profile of dental students in some colleges and universities across the country and the world is very similar to that found in the dentistry program at the School of Pharmacy, Dentistry and Nursing of the Federal University of Ceará, Brazil. There is a growing increase in the number of women enrolled in dentistry programs, which indicates a feminization of the profession. ${ }^{10-12}$ Also noteworthy is the fact that this population is predominantly composed of young students, aged 17 to 24 years, unmarried and not employed, living with parents or relatives. ${ }^{13-15}$

The socioeconomic characteristics, including family income and parental education, appear to have strong influence on students' access to higher education. Parents with a higher education degree appear to assume greater responsibility in transmitting cultural and work-related values to their children. ${ }^{16,17}$ Although there is no actual evidence that children of parents with a college degree will succeed in their first attempt to enter college, we must consider that there is a strong influence of parents with higher education on the professional success of their children, including their entry into college or university. ${ }^{16,17}$ This information corroborates the results of this study, in which most parents had a higher education degree and most students succeeded in their first attempt to enter the dentistry program.

Anxiety can be classified into physiological and pathological categories. Physiological anxiety is considered "normal" and 
part of a spectrum of daily experiences. This type of anxiety is inherent in the human race and deemed necessary as long as it works to motivate and awaken the body, putting it on guard against a threatening situation that can affect emotional stability. ${ }^{6}$ Pathological anxiety, also known as anxiety disorder, is characterized by a disproportionate response to the situation that triggers it. This type of reaction is directly related to an exacerbation of physiological symptoms, such as tachycardia, muscle aches, insomnia, poor appetite, dizziness, vomiting, and excessive tiredness, as well as of psychological symptoms, such as feelings of fear and/or insecurity, anxiety, irritability, worry, and apprehensive anticipation. ${ }^{18,19}$ Both types of anxiety can be measured by clinical self-assessment rating scales; STAI being one of the most commonly used scales to assess subjective anxietyrelated components. ${ }^{20}$

Students in the health professions, especially those enrolled in dentistry, medicine and nursing programs, usually have very high levels of anxiety compared to students from other courses, such as those in the humanities and technology. ${ }^{3}$ The main reasons for the prevalence of anxiety symptoms in these students include the complexity of the techniques practiced in the operating room, the need for psychomotor skills, extensive curriculum, in addition to internships, extracurricular activities (research, monitoring, extension and internships activities, participation in scientific events in dentistry performed during the free hours of theoretical and practical classes during the course) and shift working hours that must be completed by the end of the course. ${ }^{21-23}$

When analyzed by sex, in our study both state- and traitanxiety levels were higher for men than for women, but with no significant differences between sexes, although some studies have shown that women have higher levels of anxiety than men during university life. , $23^{2}$

In order to obtain a degree in dentistry, students are required to meet a high weekly workload and engage in a large number of extracurricular activities and training courses, which may negatively affect their academic performance and physical and mental health, triggering symptoms of

\section{REFERENCES}

1. von der Embse N, Barterian J, Segool N. Test anxiety interventions for children and adolescents: a systematic review of treatment studies from 2000-2010. Psychol Sch. 2013;50(1):57-71.

2. Coelho AT, Lorenzini LM, Suda EY, Rossini S, Reimão R. [Sleep quality, depression and anxiety in college students of last semesters in health area's courses]. Neurobiologia. 2010; 73(1):359. Portuguese.

3. Ferreira CL, Almondes KM, Braga LP, Mata AN, Lemos CA, Maia EM. [Evaluation of trait and state anxiety in first year students]. Cien Saude Colet. 2009;14(3):973-81. Portuguese.

4. Rodrigues DG, Pelisoli C. [Anxiety in candidates for university entrance examinations: an exploratory study]. Rev Psiquiatr Clín. 2008;35(5):171-7. Portuguese.

5. Soares AB, Martins JS. The anxiety of students at the expectation depression and anxiety $(24,25)$. This study found a positive association between anxiety levels and the amount of study hours and extra lessons undertaken by students per week $(p<0.000)$ and extracurricular activities performed within the university environment $(\mathrm{p}<0.000)$ (Table 5$)$.

Recent studies have found no significant differences in anxiety levels of medical students compared to students from other courses. ${ }^{22}$ Therefore, high levels of anxiety may be associated with the period of university life rather than the course itself. However, other studies suggest that obsession and perfectionism are common traits among students in the health professions, which may explain the frequent reports of anxiety, stress, depression, drug abuse and suicides among students and health professionals. ${ }^{23-25}$

In summary, most dental students investigated in this study were young single women, who had attended private high schools, lived with their parents, did not work and had their expenses paid by their families. These students, however, were engaged for 30 to 40 hours per week in activities required to meet curriculum demands of the dentistry program, in addition to performing extracurricular activities, which may have caused anxiety among the students.

\section{CONCLUSION}

From the main results, we can conclude that a significant proportion (over $50 \%$ ) of students in the Dentistry course of the Federal University of Ceará showed a medium level of anxiety, and possibly that the excessive workload and activities further necessary for obtaining the undergraduate degree may be influencing the anxiety levels of students. More studies and statistical tests should be performed to identify the main causes of high anxiety of students in order to preserve mental health and improve the quality of life of future dentists.

\section{ACKNOWLEDGMENTS}

The authors of this study would like to thank the Federal University of Ceará for financial support for the research.

of attending colleges' entrance examination. Paideia. 2010;20(45):57-62.

6. Fleiss JL, Levin B, Paik MC. Statistical methods for rates and proportions. 3rd ed. Hoboken (NJ): John Wiley \& Sons, Inc; 2003. 800 p. (Wiley series in probability and statistics).

7. Biaggio AM, Natalício L. Manual para Inventário de Ansiedade Traço-Estado (IDATE). Rio de Janeiro: CEPA; 1979.

8. Spielberger CD. Corsini encyclopedia of psychology. 4th ed. Hoboken (NJ): John Wiley \& Sons, Inc; 2010. State-trait anxiety inventory; p. 1698-9.

9. Spielberger CD. Stress and anxiety in sports. In: Hackfort D, Spielberger CD. Anxiety in sports: an international perspective. New York: Hemisphere Publishing; 1989. p. 3-13. 
10. Ioannidou E, D'Souza RN, Macdougall MJ. Gender equity in dental academics: gains and unmet challenges. J Dent Res. 2014;93(1):5-7.

11. Wallace LG, Cockrell DJ, Taylor JA. The University of Newcastle's first cohort of bachelor of oral health students: a social profile. Aust Dent J. 2010;55(4):436-40.

12. Yuan JC, Lee DJ, Kongkiatkamon S, Ross S, Prasad S, Koerber A, et al. Gender trends in dental leadership and academics: a twenty-two-year observation. J Dent Educ. 2010;74(4):372-80.

13. Cavalcanti AL, Lima WG, Marques JL, Alves HF, GranvilleGarcia AF. [Motives of the entrance and dropout of undergraduate dental students from a public institution]. Rev Odontol UNESP. 2010;39(2):95-9. Portuguese.

14. Rezende FP, Nakanishi FC, Machado AC, Quirino MR, Anbinder AL. [Profile, motivations and expectations of Dentistry undergraduates and graduates]. Revista de Odontologia da Universidade Cidade de São Paulo. 2007;19(2):165-72. Portuguese.

15. Unfer B, Rigodanzo L, Hahn D, Manfredini D, Rodrigues E, Cavalheiro CH. [Dentistry academics expectations concerning formation and future profession]. Saúde. 2004;30(1-2):33-40. Portuguese.

16. Beck HP, Milligan M. Factors influencing the institutional commitment of online students. Internet and Higher Education. 2014;20:51-6.

17. Porto JB, Tamayo A. [Parents work values influence on sons work values]. Psicol Reflex Crit. 2006;19(1):151-8. Portuguese.
18. Alzahem AM, van der Molen HT, Alaujan AH, Schmidt HG, Zamakhshary MH. Stress amongst dental students: a systematic review. Eur J Dent Educ. 2011;15(1):8-18.

19. Gama MM, Moura GS, Araújo RF, Silva FT. [Trait anxiety in brazilian university students from Aracajú]. Rev Psiquiatr Rio Gd Sul. 2008;30(1):19-24. Portuguese.

20. Fioravanti AC, Santos LF, Maissonette S, Cruz AP, LandeiraFernandez J. [Evaluation of the factorial structure of the trait anxiety scale of the STAI]. Aval Psicol. 2006;5(2):217-24. Portuguese.

21. Carvalho R, Farah OG, Galdeano LE. [Nursing undergraduates' anxiety about the first surgical instrumentation]. Rev Lat Am Enfermagem. 2004;12(6):918-23. Portuguese.

22. Pereira AM, Gonçalves MB. [Emotional disorders during medical training: a longitudinal study]. Rev Bras Educ Med. 2009;33(1):10-23. Portuguese.

23. Zuardi AW, Prota FD, Del-Ben CM. [Reduction of the anxiety of medical students after curricular reform]. Rev Bras Psiquiatr. 2008; 30(2):136-8. Portuguese.

24. Murdoch-Eaton DG, Levene MI. Formal appraisal of undergraduate medical students: is it worth the effort? Med Teach. 2004;26(1):28-32.

25. Baldassin SP, Martins LC, Andrade AG. [Anxiety traits among medical students]. Arq Med ABC. 2006;31(1):27-31. Portuguese.

\section{Como citar:}

Silva, NC, Silva BR, Vasconcelos HM, Oliveira PM, Teixeira EH, Aguiar AS. Profile of brazilian dental students and its relationship to anxiety levels. Rev Med UFC. 2015 jan-jun;55(1):25-32. 